\title{
A Escola de Enfermagem da Universidade de São Paulo e a reconfiguração da identidade profissional da Enfermagem Brasileira*
}

\author{
The University of São Paulo, School of Nursing and the Brazilian Nursing professional identity reconfiguration \\ La Escuela de Enfermería de la Universidad de São Paulo y la reconfiguración de la identidad profesional de la \\ Enfermería Brasileña
}

\section{Paulo Fernando de Souza Campos', Taka Oguisso'}

'Universidade de São Paulo. Escola de Enfermagem, Departamento de Orientação Profissional. Grupo de PesQuisa em História e Legislação da Enfermagem. São Paulo, SP

\section{RESUMO}

Este estudo pretende contribuir para a reflexão em torno das representações da identidade profissional da enfermagem brasileira. Para tanto, recupera o tema a partir de imagens construídas sobre a noção de identidade, profissionalização da enfermagem e os negros no Brasil. Considera-se Que as representações da inferioridade nata, erigidas para os negros, favoreceram a exclusão de mulheres negras da formação profissional da enfermagem. Com base na análise histórica e documentação pertinente, preservada no Centro HistóricoCultural da Enfermagem Ibero-Americana, em especial, as Fichas de Admissão, os resultados permitem afirmar Que, a Escola de Enfermagem da Universidade de São Paulo propiciou a inclusão de homens e mulheres negras na enfermagem profissional redimensionando a identidade da enfermagem brasileira.

Descritores: Papel profissional; Escolas de enfermagem; História da enfermagem.

\begin{abstract}
This study intends to contribute for reflection around Brazilian nursing professional identity. For this purpose the subject was rescued from images built up on the knowledge related to identity, nursing professionalization and the blacks in Brazil. It is considered that representations of native inferiority, raised for blacks, have favored the exclusion of black women from the professional nursing education. Based on historical analysis and pertinent documentation, preserved at the Historical-Cultural Center for the Iberian-American Nursing, particularly the admittance forms, outcomes allow to state that the University of Sao Paulo, School of Nursing, has provided the inclusion of men and black women into the professional nursing, thus re-dimensioning the Brazilian Nursing identity.
\end{abstract}

Descriptors: Professional role; Nursing schools; History of nursing.

\section{RESUMEN}

Este estudio pretende contribuir para la reflexión alrededor de las representaciones de la identidad profesional de la enfermería brasileña. Para tanto, se recupera el tema a partir de imágenes construidas sobre el concepto de identidad, profesionalización de la enfermería y los negros en Brasil. Considerase que las representaciones de inferioridad nativa, erigidas para los negros, favorecieran la exclusión de mujeres negras de la formación profesional de enfermería. Embasado en un análisis histórico y documentación pertinente, preservada en el Centro Histórico-Cultural de la Enfermería Ibero-Americana, en especial, los registros de Admisión, los resultados permiten afirmar Que, la Escuela de Enfermería, de la Universidad de São Paulo ha favorecido la inclusión de hombres y mujeres negras en la enfermería profesional redimensionando la identidad de la enfermería brasileña.

Descriptores: Rol del profesional; Escuelas de enfermería; Historia de la enfermería. 


\section{REPRESENTAÇÕES: A CONSTRUÇÃO DA IDENTIDADE}

É possível definir identidade de uma pessoa como algo individual, com um conjunto de caracteres próprios e exclusivos como: nome, filiação, local e data de nascimento, profissão, sexo, e principalmente se pensada através das impressões digitais - marcas Que caracterizam a identidade de uma pessoa. A identidade coletiva seria o conjunto de características pelas Quais algo é definitivamente reconhecível ou conhecido. A identidade profissional seria um tipo de identidade coletiva, com base em traços ou características comuns a todos Que exercem determinada atividade. Fala-se também em identidade visual Que poderia ser a personalidade visual de uma empresa, resultante de efeito interativo das características comuns de suas imagens visuais, como o conjunto de elementos gráfico-visuais padronizados como a cor, o logotipo, uniforme, embalagem, tipo de letra e outros fatores que constituem marcas para torná-las conhecidas na sociedade. Essas marcas são geralmente protegidas por patentes nacionais e internacionais para evitar Que outros possam usar ou deles tirar proveito.

$\mathrm{Na}$ enfermagem a própria denominação, enfermeiro ou enfermeira, não ajuda muito a definir a profissão, sobretudo para o público leigo, porque liga o nome a enfermo, doença ou enfermidade Quando o profissional tem hoje uma atuação muito mais ampla e profunda. Até algumas décadas atrás, a denominação era cercada de preconceito, de tal forma Que a Associação Brasileira de Enfermagem (ABEn) lutava pela melhoria do status profissional, combatendo o mau uso da palavra, muitas vezes ligada ao exercício de pessoas sem preparação alguma ou com preparação inadeQuada ou insuficiente ou mesmo a atividades sem compromisso com a moral e bons costumes, identificando a enfermeira (sua principal personagem) como mulher sedutora, inescrupulosa e vulgar.

É importante observar Que tal preconceito já existia nos tempos de Florence Nightingale. A novela escrita por Charles Dickens The Life and Adventures of Martin Chuzzlewit revela os perfis da enfermagem pré-nightingaleana ao construir a personagem Sarah Gamp como gorda, viciada, mercenária, com desvios de caráter Que associavam as antigas cuidadoras a um universo decadente e imoral $^{(1)}$. A identidade da nurse, como descrita no romance vitoriano, ainda Que metaforicamente, desvela aventuras e horrores vividos por homens e mulheres na passagem do século XVIII para o século XIX, cujas transformações atingiam os comportamentos públicos e privados, alterando as formas de vida e trabalho existentes, abordagem histórica importante para a reflexão sobre o cuidado no período, assim como Quem o executava. A imagem de Sarah Gamp evoca um momento importante para a história das mulheres, pois faz emergir novas sociabilidades em um novo espaço social: as cidades.

Outra evidência Que corrobora para essa representação e a existência de uma escola de enfermagem na Alemanha, freqüentada por Florence Nigthingale, Que formava cuidadoras, chamada Deaconess Institute at Kaiserwerth. Segundo Molina, as formadas eram chamadas diaconisas a fim de evitar a errônea interpretação Que se dava à palavra enfermeira, profissão subestimada na época, ora interpretada como consagrada, ora como algo profano, vulgar, condenável. Além disso, a Igreja Católica difundiu também a idéia de diaconato, diácono e diaconisa, relacionando-a com cuidado de doentes e religião, como uma antecipação da profissão, tal Qual fora Febe, diaconisa que cuidou de São Paulo ou Olímpia, citada por São João Crisóstomo(2).

No Brasil, em meados da década de 1960, a ABEn tentou mudar o nome da profissão, solicitando a intelectuais das letras e acadêmicos da Academia Paulista de Letras, Que ajudassem a encontrar um nome Que definisse melhor Quem era enfermeiro. A antiga parteira havia encontrado um nome distinto e elegante como obstetriz, assim como o profissional da alimentação surgiu como nutricionista. Para o enfermeiro houve inicialmente a sugestão do termo enfermólogo, sugestão logo abandonada porque continuava vinculada a enfermo e enfermidade, sem atinar com saúde. Outra sugestão era o título de tecnólogo da saúde Que, de tão amplo nada significava, pois QualQuer profissional da saúde poderia perfeitamente intitular-se tecnólogo, e além do mais, a enfermagem não era e nem podia ser apenas tecnologia. Era necessário aliar tecnologia com humanismo, com cuidado de pessoa a pessoa e relacionamento inter-pessoal, pois enfermagem é gente Que cuida de gente ${ }^{(3)}$.

Com toda a evolução Que a máouina possa vir a ter, ela nunca poderá substituir o profissional enfermeiro. As nuances e filigranas de um instante de relacionamento profissional do enfermeiro, com seu olhar atento, observador e tecnicamente acurado ao visitar ou ver seu paciente ou cliente, no hospital, no domicilio ou em Qualeuer serviço de saúde, devem substituir as máeuinas mais sofisticadas Que para funcionarem corretamente necessitam ser adequadamente alimentadas com informação precisa e correta. Muitas vezes o paciente não consegue expressar corretamente seus próprios sintomas, seja pelo estado de consciência, seja pela dificuldade em definir e identificar o Que sente. E o enfermeiro deverá ser capaz de identificar sinais subjetivos e objetivos e fazer perguntas Que o auxiliem a caracterizar auilo Que sente.

Enfermeiros norte-americanos também se Queixam de Que a palavra Que os define como profissão é ampla demais, de modo Que tudo cabe nela, desde nutrir, alimentar até cuidar de pessoa doente ou ferida. Existem ainda expressões como to nurse, wet nurse ou nursing mother Que significam, dar o seio, alimentar ou mulher que amamenta filho de outra pessoa (como a ama de leite no Brasil). Entre muitos outros significados, o termo por muito tempo provocou várias representações. Assim, a casa de repouso para idosos é chamada nursing home e o berçário, creche ou espaço para crianças de nursery, embora possa ser assim chamado o viveiro para cultivo de plantas.

Em francês a palavra enfermagem não existe, só enfermeiro e enfermeira. Assim para significar enfermagem utiliza-se a palavra soins Que significa cuidado, assim soins infirmiers seriam os cuidados prestados por um enfermeiro; como sage-femmes, sage-femmes jurées, cuja tradução implica considerar as ações das parteiras, mulheres experientes no cuidado às parturientes. Em sueco e outros idiomas nórdicos não existe nem a palavra enfermagem e nem enfermeiro, definindo-os como profissão e profissionais de saúde. Mesmo, em português não existe verbo nem adjetivo da palavra enfermagem, pois enfermar não é fazer enfermagem, mas sim ficar doente. Por isso, utilizam-se verbos como prestar, dar, assistir, cuidar, fazer, atender entre outros ${ }^{(4)}$.

Como se observa, as definições, por mais exatas Que possam parecer, exigem constantes revisões, tanto no Que concerne ao exercício da profissão, Quanto às especificidades histórico-culturais. 
A identidade profissional da enfermagem brasileira não pode ser avaliada somente a partir de imposições dadas por um modelo hegemônico, proposto como padrão à profissionalização da enfermagem brasileira, filtrado pelo olhar estrangeiro, logo, estanque às Qualidades e características do espaço social no Qual foi (re)produzido. A imposição de valores opera como formador de opinião, imprescindível à construção dos sentidos e à atribuição dos significados Que identificam coisas e pessoas.

\section{IDENTIDADE PROFISSIONAL: IMAGENS PRODUTORAS DE VERDADES}

Quando se escreve a história de uma profissão, existe facilmente a tendência de buscar suas origens no passado mais remoto da humanidade com o perigo de forçar exageradamente os fatos históricos. A tendência mais comum é enfatizar a profissão por intermédio de virtudes como bondade, paciência, dedicação, abnegação, e em especial atitudes de passividade como, obediência, submissão, respeito ao médico e outros superiores e às instituições. Tais imagens derivavam respectivamente de representações históricas distintas: a imagem mais primitiva da enfermeira era a imagem popular de alguém Que prestava cuidado simples e maternal e a imagem do médico era de um homem respeitado, em lugar superior, por causa de seus conhecimentos especiais; ainda Que historicamente fossem as mulheres as Que inicialmente detiveram o conhecimento das curas, pois se incumbiam da preparação de alimentos manipulando ervas, bulbos, essências, flores, pétalas, raízes e toda a sorte de líquidos e carnes, descobrindo seus princípios ativos, logo, seus usos medicinais ${ }^{(4)}$.

A literatura menciona Que há três imagens associadas com enfermeira: a de mãe Que cuida do filho, de doentes ou feridos; a da religiosa Que cuidava de alguém como parte do cumprimento do dever cristão e a da enfermeira-servidora Que surgiu na Europa protestante a partir do século XVI. A enfermeira-mãe não necessitaria de preparação profissional, pois se considerava Que ela teria intuição para fazer as coisas corretamente, e assim não necessitava de preparo especial; a imagem da enfermeira-monja pode ter sido um obstáculo para o reconhecimento de direitos, inclusive econômicos da enfermeira e pode ter fomentado uma obediência cega ao médico e superiores; finalmente a imagem da enfermeira-servidora, dentro dessa mesma linha de submissão e obediência, não suscitou maior preparação profissional da enfermeira, pois era vista como uma religiosa sem o hábito.

Nesse processo de busca por uma identidade, não é fácil saber o Que efetivamente delimita uma profissão. Discute-se muito sobre o presente e o futuro do profissional enfermeiro, mas é necessário definir o núcleo da profissão, de forma clara, incontestável e aceita por todos os pares, sem sofismas e silogismos, definindo-se o enfermeiro pelo que ele é e não pelo Que faz. Virginia Henderson propôs sua primeira definição de enfermagem, na década de 1960 , aceita por todos e por muito tempo, descrevendo Que consiste em "assistir ao individuo enfermo ou sadio na realização de atividades Que contribuem para sua saúde ou recuperação dela (ou ainda uma morte tranQüila) e que ele faria sozinho se tivesse força, vontade ou conhecimentos necessários". Posteriormente, essa definição foi considerada insuficiente por centrar-se no indivíduo e deixar de lado o âmbito comunitário e social. Marian McGee define como um "processo de interação enfermeiro-paciente Que provem do reconhecimento das necessidades e níveis de capacidade do enfermo, com possibilidade de adaptação do ambiente, do comportamento e da atenção e manutenção biológica"(5).

Muitas vezes, definições mais complicam do Que explicam os significados e alcances de uma profissão. No caso da enfermagem a preocupação de se dar um cunho cientifico e tecnológico, acabou por dar uma exagerada primazia aos aspectos puramente técnicos e profissionais, esquecendo-se de alguns aspectos sociais e até vocacionais, como interesse pelo ser humano e desejo de servi-lo em QualQuer situação de saúde ou doença, mas, em especial, em situações de necessidade ou dependência.

\section{ENFERMAGEM BRASILEIRA: O BRANQUEAMENTO DO CUIDADO}

Assim, pode-se afirmar que identidade é algo singular, Que confere Qualidades e exclusividade ao individuo. A análise permite perceber Que a noção de identidade implica na atribuição de significados Que respaldam os entendimentos e as interpretações Que as pessoas têm de si mesmas, do grupo a Que pertencem ou do Que consomem. Por exemplo, Quando pensamos em enfermagem ou enfermeiro evocamos códigos, imagens, representações Que, dadas a priori, nos permitem reconhecer pessoas, abstrair conceitos, visualizar lugares, paisagens e legitimá-las como tal. Assim, a perspectiva faz pensar que identidade é ao mesmo tempo algo mutante e mutável, revelada pela inexorável condição biológica Que torna as pessoas únicas, tanto como pela cultura, profissão e estilo de vida adotado ${ }^{(6,7)}$.

Contudo, as constatações permitem considerar Que a noção de identidade constrói o outro, pois forja comportamentos, produz reações e representações. Nesta perspectiva, é possível supor Que a identidade, ao mesmo tempo em Que confere unicidade, pode ser excludente, discriminatória e intolerante, na medida em Que refuta experiências adversas, contrárias às preconizadas como ideais. Conforme aponta Roger Chartier $^{(8)}$, representações são construções Que visam fins específicos, portanto, não podem ser analisadas como discursos neutros, pois produzem práticas Que legitimam determinados projetos. O autor ressalta que “...embora aspirem a universalidade (as representações) são sempre determinadas pelos interesses de um grupo Que as forjam".

Transpostas para o social, a racionalidade Que define identidade, invariavelmente determina trajetórias, elimina singularidades e acontecimentos por considerá-los pouco informativos, efêmeros, ordinários, manipulando opiniões e a escrita da história. A imposição de uma identidade pode, nestes termos, cristalizar representações acerca do Que se pretende alcançar, mas também lhe é contrário. Nessa medida, passa a identificar aquilo Que não é, ou que é adverso, abjeto, sobretudo por não se coadunar com a ordem assumida como verdadeira ou ideal.

No âmbito da história da enfermagem, um primeiro anacronismo é a identificação da profissão como eminentemente feminina. Não é incomum encontrar em textos acadêmicos, publicitários, jornalísticos, imagens Que revelam a enfermagem como ação praticada por mulheres, idealizada para sua principal personagem: a enfermeira. Assumidas como correlato de verdade, as representações da enfermagem, Que define a profissão como 
"própria para mulheres", interferiu poderosamente na formação da identidade profissional, sobretudo no caso brasileiro, pois ampliadas, as representações da enfermagem identificavam como ideal para a profissão um determinado tipo de mulher, Qual seja, branca, culta, jovem, saudável. Neste sentido, não incluía homens e tampouco mulheres negras, ainda Que estes existissem ${ }^{(1,6)}$.

Partindo deste pressuposto, as representações raciais e de gênero contribuíram para a legitimação de uma identidade profissional excludente e discriminatória. Transpostas para a realidade local, as representações dominantes da identidade profissional da enfermagem brasileira encontram forte ressonância com as representações construídas sobre o brasileiro. Estudos produzidos em diversas áreas do conhecimento permitem afirmar Que a identidade do povo brasileiro é fundada no abrandamento de acontecimentos violentos, trágicos, pouco revelados pela historiografia, como os Que dizimaram "povos exóticos" Que habitavam o novo mundo, "substituídos" por negros africanos escravizados, forjando uma identidade nacional às avessas, contrária à realidade local. Porém, mesmo com a instauração da República, diferenças entre brancos e negros permaneceram incólumes até, seguramente, a década de 1950; período no Qual a sociedade brasileira rediscute a presença negra no país, contudo, sem alterar comportamentos ou interpretações históricas.

Sintomaticamente, a instauração da República evoca um dos grandes momentos da saúde pública brasileira, assim como recupera um dos marcos da história da enfermagem no Brasil, conhecida como Missão Parsons $^{(9)}$. A historiografia dominante indica Que as vicissitudes do novo regime resultaram em reformas sanitárias, instauração de políticas de saúde pública, criação de campanhas, ligas, associações, escolas e outros espaços institucionais, reafirmando Que a Questão da saúde no Brasil polarizou os investimentos durante a Primeira República (1889-1930).

Concentrados em esforços políticos, os movimentos em torno da saúde pretendiam reverter a representação do país, visto como um local impuro, viciado, pestilento, propício ao desenvolvimento de doenças, inclusive, por sua característica maior, a miscigenação de sua população. Econômica e politicamente desfavorável, a visibilidade dominante deveria ser alterada. Para tanto, cidades foram higienizadas, habitações populares e coletivas destruídas, ruas e avenidas remodeladas e a população branqueada com a entrada massiva de imigrantes, o Que também preocupava médicos, sanitaristas e eugenistas Que viveram no século passado. A comunicação proferida por Renato Kehl, um ilustre médico do período, durante os eventos do Primeiro Congresso Brasileiro de Eugenia, realizado no Rio de Janeiro, em 1929, permite entrever as representações do negro no Brasil:

Senhores, O Brasil precisa augmentar o seu stock de homens válidos. O poder de uma nação se aQuilata pelo valor dos indivíduos Que a integram. Nada se diz de novo Quando se affirma "Que não existe interesse ou bem estar da sociedade distincto do interesse e bem estar de seus membros". O nosso stock de homens, physica e mentalmente superiores, é diminuto (...) Pergunto a mim mesmo: será isso conseeüência da mistura das raças, será isso o que pintou Paulo Prado no "Retrato do Brasil"? Será um mal insanável? (sic) ${ }^{(10)}$.

A República nascia com a missão de regenerar o país ainda atado ao seu passado colonial. No pensar das elites políticas e dominantes, a profilaxia, a saúde pública e as mudanças de hábitos cotidianos conduziriam os brasileiros para o estado mais avançado da vida em sociedade. Tais protocolos impunham regras para morar, vestir-se, comer, cuidar da saúde, projetados por discursos médicos Que visavam controlar o social. Entretanto, como analisou Jurandir Freire Costa, a imposição das normas médicas redefiniram a visibilidade do negro "...fazendo-o portador de uma força incoercível, a força da doença e da imoralidade..."(II).

Para o alcance dos objetivos propostos pela República (sanar um país doente) era preciso controlar as populações, interromper os "vícios da hereditariedade", os desvios da moral, originários da mistura racial. Identificados como inferiores, a imensa maioria de negros, pardos, mulatos, pretos, assumiam funções sociais desprestigiadas, dificultando ainda mais a participação do negro na sociedade mais ampla e, no caso específico, impedindo Que mulheres negras ingressassem na enfermagem profissional. No âmbito específico da enfermagem brasileira, Barreira permite considerar Que as representações dominantes, construídas sobre os negros, influenciaram a formação da liderança da enfermagem nacional. De acordo com a autora, “...várias das candidatas Que atenderam aos apelos humanitários e patrióticos dos médicos sanitaristas provinham da classe média alta da sociedade, muitas delas tendo sido diretamente por eles recrutadas. Não obstante, candidatas oriundas de famílias pobres poderiam ser bem recebidas, mas o mesmo não ocorreria com as candidatas negras..."(1).

No Que concerne à Questão étnica, a história da enfermagem brasileira, desde seus primórdios, evidencia embates provocados por tentativas de ingresso de mulheres negras em escolas de enfermagem. Um desses episódios originais, vivido por dirigentes e alunas da Escola de Enfermeiras, do Departamento Nacional de Saúde Pública, Rio de Janeiro, fundada em 1923, o problema gerado pela segregação racial nas origens da formação da identidade profissional da Enfermagem brasileira é bastante esclarecedor:

É verdade Que a política de organização da escola tinha sido evitar, diplomática e estrategicamente, a admissão de negros, até Que a opinião pública em relação à profissão de enfermagem tivesse mudado. Isto era fundamental se se pretendia atrair mulheres de melhor classe... mesmo a Academia Naval colocava obstáculos para impedir a admissão de candidatos negros. Todas as vezes em Que moças de cor se candidatavam para entrar na escola, havia sempre outras boas razões para Que elas não fossem Qualificadas, por isso nenhum problema havia surgido até então. Na verdade, havia já na escola três estudantes Que, apesar de brancas, mostravam alguns traços de sangue negro. Foi enviada uma carta à imprensa comunicando Que nenhuma pretendente havia sido rejeitada por causa da cor, mas não foi convincente, e o Departamento de Saúde achou Que seria aconselhável permitir o ingresso de uma moça negra, se acaso se apresentasse alguma Que preenchesse todos os reQuisitos para a admissão. Esta candidata apareceu em março (1926), juntamente com as demais pretendentes sob forte suspeita de Que havia sido mandada por um dos jornais, e foi admitida. Isto provocou uma enxurrada de protestos por parte da alunas, mas, após considerar a Questão, o Conselho de Estudantes finalmente decidiu Que QualQuer manifestação de rejeição ou de descortesia para com uma colega de classe demonstraria falta de respeito e de vontade de cooperar, e assim não houve mais dificuldades. As estudantes deixaram claro, contudo, Que esperavam Que não fosse admitida nenhuma outra negra por algum tempo ${ }^{(12)}$. 
O registro torna-se revelador pois além de fundamentar as análises em pauta, amplia o debate em torno da trajetória histórica das populações afro-brasileiras. A admissão de uma negra e outras "....Que apesar de brancas, mostravam alguns traços de sangue negro..." no interior dos Quadros acadêmicos da escola, revela que a tese da ignorância não mais se sustentava. Ainda assim, a onda de protestos Que se seguiu após admissão de uma moça negra permite afirmar Que as representações da degenerescência moldavam os comportamentos das eleitas para dirigir a enfermagem brasileira.

O episódio comprova Que independentemente da origem étnica ou condição social, mulheres negras poderiam preencher os prérequisitos exigidos a uma futura profissional. Ao analisar o Relatório Anual do Serviço de Enfermagem, encaminhado por Ethel Parsons ao Departamento Nacional de Saúde Pública, em 1926, Barreira novamente menciona a Questão da discriminação racial na seleção de candidatas a alunas da Escola de Enfermagem Anna Nery ${ }^{(10)}$.

As considerações da autora consubstanciam as inferências, pois indica Que as recusas funcionavam como parte de um projeto político, de formação da liderança da enfermagem nacional. Contudo, a efetivação do projeto forjou a memória da enfermagem brasileira, pois desconsiderou práticas Que a nova história da enfermagem, em parceria com a antropologia dos cuidados, tem permitido acessar, como a experiência das amas de leite, babás, mães pretas, todas cuidadoras; assim como realizações no campo do ensino e da assistência de enfermagem, Que incluíam homens ${ }^{(13,14)}$, permite reconhecer em seus estudos sobre a Escola de Enfermeiros e Enfermeiras Alfredo Pinto, cujo modelo de ensino não se coadunava com o novo projeto para enfermagem brasileira, originalmente proposto por enfermeiras norte-americanas com o apoio de Carlos Chagas.

Do ponto de vista da "raça”, Luis Antonio de Castro Santos e Lina Rodrigues de Faria, indicam Que a Questão, no âmbito da enfermagem, merece ser "investigada a fundo", supondo que os investimentos no setor agiram no sentido de propiciar a mobilidade e ascensão social de negros. De fato, na década de 1940, com a fundação da Escola de Enfermagem, da Faculdade de Medicina, da Universidade de São Paulo, a percepção da diferença racial no âmbito da enfermagem assume outros contornos ${ }^{(15)}$.

\section{NOVAS DIMENSÕES: HOMENS E MULHERES NEGRAS NA ESCOLA DE ENFERMAGEM}

As análises empreendidas permitem afirmar Que partir da segunda turma, em 1943, a Escola de Enfermagem da USP já contava com alunas negras. Josephina de Mello, uma das alunas não brancas é um caso contundente. Seus registros indicam Que era filha de uma inglesa e enfermeira obstétrica Que trabalhou em Bridgetown, Barbados e de um cirurgião que trabalhava em Manaus, no Estado de Amazonas. Bolsista do Serviço Especial de Saúde Pública (SESP), a aluna trabalhava na capital daquele Estado "no Posto de Assistência Médica, do bairro de Girau, mantido pela Legião Brasileira de Assistência" Quando teve seus estudos financiados, mudando-se para São Paulo. Normalista diplomada, a ex-aluna concluiu o curso da Cruz Vermelha Brasileira para "enfermeira de emergências", dados que permitem afirmar Que ao matricular-se, a aluna atuava na área da assistência de enfermagem no Estado do Amazonas.

Entre os registros acadêmicos Que constam de seu dossier, há uma ficha de matrícula do Ministério da Educação e Saúde, Universidade do Brasil, Escola Anna Nery, na Qual a postulante responde um Questionário similar ao Que era solicitado pela EEUSP. O documento permite considerar Que Josephina de Mello, uma jovem protestante, não ingressou na escola de enfermagem em pauta. $\mathrm{O}$ Que teria acontecido com Josephina de Mello? Porque a ficha de admissão da Escola Ana Nery foi arQuivada juntamente com os documentos da Escola de Enfermagem da USP? Por outro lado, é possível inferir que as duas escolas polarizavam a formação de enfermeiras oriundas do interior do Brasil, inclusive por estabelecer acordos com a Fundação SESP no movimento de expansão da enfermagem no Brasil.

Outra bolsista do SESP Que se declara não branca, Lucia Conceição da Costa, indicava ser necessário o financiamento por

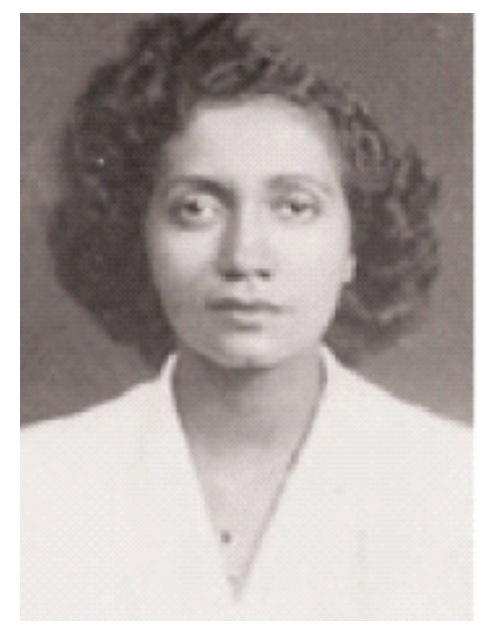

1944

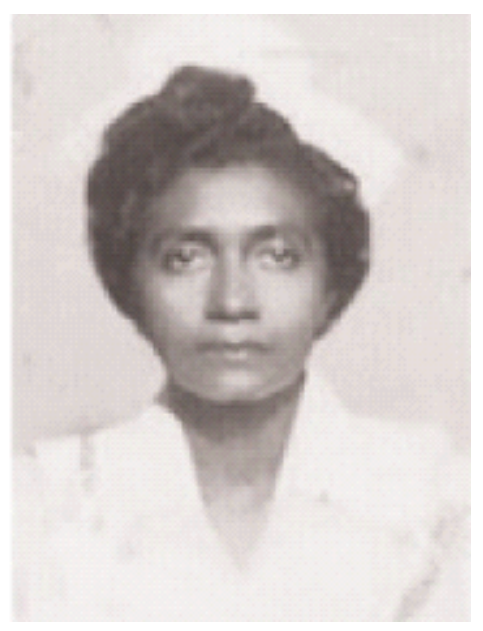

1947

Fonte: Acervo do Centro Histórico Cultural da Enfermagem Ibero-Americana

Josephina de Mello. 


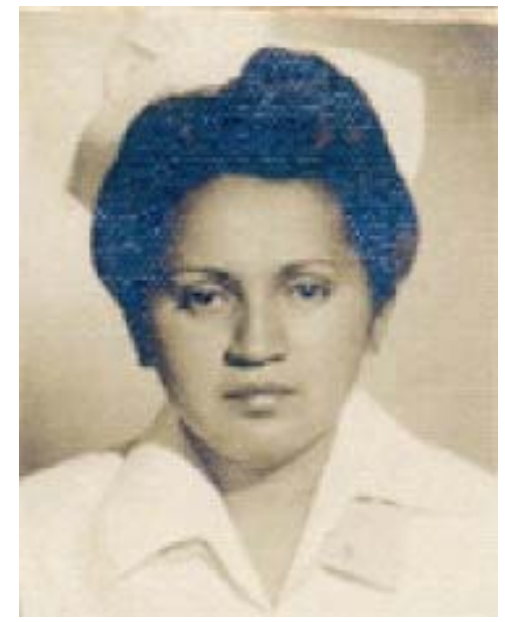

1947

Fonte: Acervo do Centro Histórico Cultural da Enfermagem Ibero-Americana

\section{Lúcia Conceição da Costa.}

não possuir recursos para manter os gastos com a formação profissional, permitindo considerar Que era uma aluna de recursos modestos, problema ampliado por ter responsabilidade com a formação de uma das irmãs menores, como permite constatar a documentação compulsada.

Detalhes como estes são comuns nas fichas das alunas negras, mulatas, morenas e pardas. Ainda Que alunas brancas também necessitassem do auxílio, as informações permitem considerar Que na maior parte dos casos, se tratavam de mulheres pobres, sem muitas posses, mas que de alguma forma estavam inseridas no universo do cuidado, atuando como professoras, visitadoras sanitárias, samaritanas, voluntárias, socorristas e auxiliares de médicos. Exemplar neste sentido, Lucia afirmou ter trabalhado como Visitadora de Saúde e ter feito cursos na área, dois cursos de Visitadora de Saúde, em 1938, e um de Samaritana da Cruz Vermelha, em 1943.

Ao indicar os motivos Que a teriam levado a escolher a profissão e a escola de São Paulo, revela: "Escolhi a profissão de enfermeira pela satisfação íntima Que sinto toda vez Que se apresenta oportunidade de aliviar moralmente ou fisicamente o ser humano". Oriunda de Marajó, no Estado do Pará, a bolsista compunha o Quadro das alunas não brancas diplomadas pela Escola de Enfermagem.

As mulheres não brancas formadas pela Escola de Enfermagem, da Faculdade de Medicina, da Universidade de São Paulo (EEFMUSP), além de vencerem preconceitos, revogavam representações atribuídas à enfermagem brasileira. Mesmo Que oriundas das classes pobres e médias da sociedade brasileira, as negras que estudaram na EEFMUSP eram mulheres bem instruídas, de alguma forma contrária aos imperativos seculares Que destinavam as mulheres ao recôndito do lar e da maternidade na medida em Que se dedicavam ao trabalho e outras ocupações, geralmente vinculadas aos programas Que o SESP mantinha no interior do Brasil, com destaque para a região norte e nordeste. Entretanto, a inclusão de mulheres negras na enfermagem profissional ocorreu à revelia dos padrões sociais e estéticos dominantes, suscitando sentimentos contraditórios, muito provavelmente dolorosos às futuras enfermeiras negras, Que se despojavam dos poucos bens Que possuíam para viver longe de seus familiares, em um ambiente totalmente novo, inusitado para muitas destas mulheres.

O primeiro homem a estudar na Escola de Enfermagem da USP foi Benoni de Sousa Lima, nascido em "Porto-Velho, então Amazonas, hoje território do Guaporé", como consta em sua documentação, no dia 14 de abril de 1918. Filho de Aristides de Souza Lima, telegrafista falecido por "colapso cardíaco" e Osvaldina Queiroz de Lima, Que se ocupava das "lides domésticas", o primeiro aluno da Escola, ao ser aceito como pioneiro do gênero no curso de enfermagem, antes de morar em São Paulo, morava "sozinho no Hospital do Perpétuo Socorro" na cidade de Guajará Mirim, no Qual trabalhava como "Enfermeiro Auxiliar”. Sua história de vida permite observar Que estudou o curso primário e secundário no Liceu Cuiabano, na cidade de Cuiabá, Mato Grosso, "sendo transferido paro o Colégio Santa Tereza de Corumbá, onde terminou o curso depois de Quatro anos de interrupção por falta de recursos".

Suas declarações permitem observar Que o mesmo conhecia outras cidades, além de São Paulo, Piracicaba, Uberaba e Campo Grande. As informações reiteram Que o candidato admitido possuía conhecimentos na área, na Qual demonstrava ser atuante. Interrogado sobre empregos anteriores, Benoni de Sousa Lima responde positivamente, afirmando que havia trabalhado como "laboratorista. Microscopista e Enfermeiro Prático (...) em diversos Postos de Higiene do Estado do Mato-Grosso, Centro de Saúde e Hospitais".

$\mathrm{O}$ aceite do primeiro homem a estudar na Escola implica supor Que a enfermagem nacional, fundada na representação dominante da enfermeira, perdia sua hegemonia, ou ainda, reinseria o homem na formação profissional, cuja contribuição inclui a Cruz Vermelha Brasileira. Ainda Que a inclusão de homens e mulheres negras na enfermagem estivesse em curso, as vicissitudes deste processo não foram aceitas de forma pacífica ou uni-direcionalmente. Em sua postulação, Beneni declarava:

Desejo ser enfermeiro diplomado não só por aperfeiçoar meus 


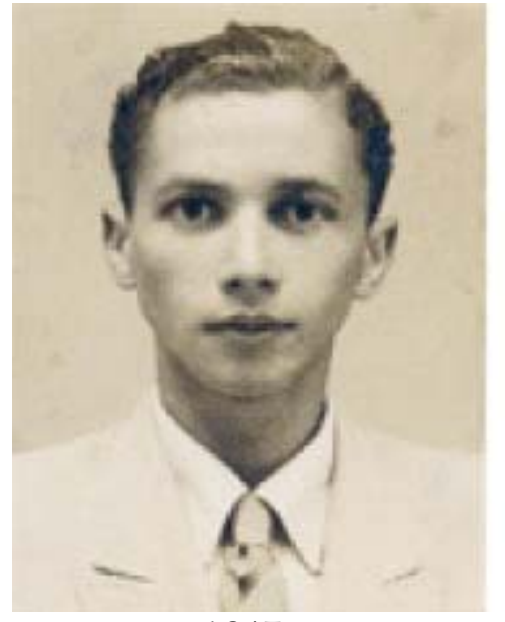

1947

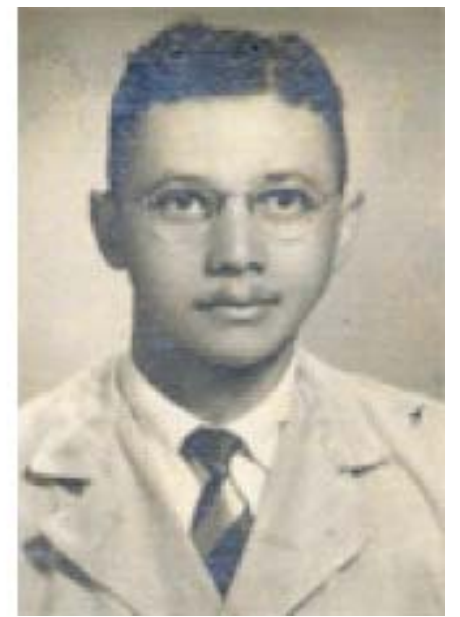

1951

Fonte: Acervo do Centro Histórico Cultural da Enfermagem Ibero-Americana

Benoni Sousa Lima.

conhecimentos práticos, como também por considerar esta profissão a Que me vem dando o pão de cada dia, a mais bela das artes. Outrossim, em face do alto desenvolvimento da medicina, Que necessita de auxiliares capazes e conhecedores da verdadeira arte da enfermagem Que exige atualmente não só conhecimentos sob bases científicas, grande abnegação e piedade. E mesmo para poder desempenhar conscientemente a alta missão de enfermeiro. Guajará-Mirim, 28 de janeiro de 1947.

Os argumentos Quase litúrgicos Que pretendiam justificar sua presença na escola para mulheres, ao mesmo tempo em Que recupera origens religiosas do cuidado, executado ou proposto por padres e pastores, como São João de Deus ${ }^{(16)}$, na Espanha
Quinhentista e Theodor Fliedner (1800-1864) na Alemanha protestante $^{(2,17)}$, o discurso de Benoni implica considerar que a presença masculina na enfermagem encontrou na religião uma das possibilidades de acesso no ensino profissional pós-padrão Anna Nery, Que a Escola de Enfermagem de São Paulo propiciou.

Diferentemente das antigas representações, Que ora apresentavam as enfermeiras presas aos reducionismos do cuidado, como ato de caridade e benevolência, ora como exercício profissional apropriado para moças, filhas das elites brancas, os homens e as mulheres negras redimensionaram a visibilidade da enfermagem brasileira, enfrentando o universo restritivo da enfermagem profissional.

\section{REFERÊNCIAS}

I. Miranda CML. O risco e o bordado - um estudo sobre a formação da identidade profissional. Rio de Janeiro: Escola de Enfermagem Anna Nery/UFR); 1996.

2. Donahue P. Nursing. The finest art. An Illustrated History. $2^{\text {nd }}$ ed. Saint Louis: Mosby; 1996.

3. Horta W. Da necessidade de se conceituar a enfermagem. Enferm Novas Dimens 1975; I(1): 5-7.

4. Collière M-F. Promover a Vida. Da pratica das mulheres de virtude aos cuidados de enfermagem. Lisboa: Lidel; 1999.

5. McGee M. American Jour Nurs 1971; 71 (7):1438-40.

6. Souza Campos PF, Oguisso T. Exclusión de mujeres negras. Su Representación en la Enfermeria Profesional. Rev Index Enferm 2006; (55): 27-31.

7. Santos GA. A invenção do Ser Negro. Um percurso das idéias Que naturalizaram a inferioridade dos negros. São Paulo (SP): Educ-Pallas-Fapesp; 2002.

8. Chartier R. O mundo como representação. Rev Estudos Avan 1991; 5(11): 173-91.

9. Barreira I A. Os Primórdios da Enfermagem Moderna no Brasil. Esc Anna Nery Rev Enferm 1997; I(1): 161-76.
10. Kehl R. A Campanha da Eugenia no Brasil. Are Bras Hyg Mental 193 I I (2): 12-22

11. Costa JF. Ordem médica e norma familiar. $4^{\mathrm{a}}$ ed. Rio de Janeiro: Graal; 1999.

12. Moreira $\mathrm{MCN}$. A Fundação Rockefeller e a construção da identidade profissional de enfermagem do Brasil na Primeira República. História Ciências Saúde - Manguinhos 1998; (3): $62 \mathrm{I}-45$.

13. Moreira A, Oguisso T. Profissionalização da Enfermagem Brasileira. Rio de Janeiro: Guanabara Koogan; 2005.

14. Porto F, Amorim W. História da Enfermagem Brasileira. Lutas, ritos e emblemas. Rio de Janeiro: Águia Dourada; 2007.

15. Santos LAC, Faria LR. A Cooperação Internacional e a Enfermagem de Saúde Pública no Rio de Janeiro e São Paulo. Horizontes 2004; 22(2): 123-50.

16. Freitas GF, Oguisso T, Siles González I. Anthropology and Caring in the View of Saint John of God. In: American Association for the History Association. Sept 25-27, 2008; Philadelphia (PA), USA. Philadelphia (PA): AAHN; 2008. p. 17.

17. Oguisso T. Trajetória histórica e legal da Enfermagem. $2^{\text {a }}$ ed. Barueri: Manole; 2007. 